\title{
Coping Repertoire in Caregivers of Schizophrenic Patients: An Indian Study
}

\author{
Dr. Aditya Gupta ${ }^{1}$, Dr. R. K. Solanki ${ }^{2}$, Dr. G. D. Koolwal ${ }^{3}$, Dr. Sanjay Gehlot ${ }^{4}$ \\ 1. Department of Psychiatry, Dr. S.N. Medical College, Jodhpur \\ 2. Sr. Professor \& Head, Department of Psychiatry, Dr. S.N. Medical College, Jodhpur \\ 3. Sr. Professor, Department of Psychiatry, Dr. S.N. Medical College, Jodhpur \\ 4. Professor, Department of Psychiatry, Dr. S.N. Medical College, Jodhpur
}

\begin{abstract}
:
Introduction: There is a definite paucity of Indian studies looking into the coping repertoire of schizophrenic patients as a whole and its relationship with the socio-demographic variables. So the current study aims to study the same.

Methods: The sample included 100 patients with a diagnosis of schizophrenia and their caregivers, randomly selected from the patients admitted in the male and female wards of psychiatric centre, Jodhpur as per inclusion and exclusion criteria. Coping Checklist was used for the study.

Results: A larger coping repertoire was found in younger caregivers and those with higher educational status. Highest mean coping score was found in the siblings while parents reported least mean coping score.

Conclusion: Quality of care given to the schizophrenic individuals rests on their primary care giver. It thus becomes essential to plan interventions that would increase their coping repertoire and thus improve their psychological well being.
\end{abstract}

Key words: caregivers, coping, schizophrenia

\section{Introduction}

Schizophrenia is considered a severe, disabling and chronic mental illness characterized by fundamental distortions in thinking and perception that requires care for almost the entire life span of the affected individual. Such severe mental illness has a devastating impact on the patient as well as his or her family members. Patient experience problems related to both positive symptoms such as aggressive behavior, delusions, hallucinations and negative symptoms such as poor motivation and inadequate self-care. The capacity for social relationship is often diminished, and employment opportunities are reduced (Lefley H.P. 1989; Van Wijingaarden et al 2002). Modern methods of treatment have helped a large number of patients to recover or to improve significantly, but many continue to display deficits in several areas of functioning. Thus chronic mental illness poses a heavy burden on the patient, the family and the community.

Patient's relatives experience a range of emotions, from loss and grief to guilt and anger. Like the patient they also feel isolated and stigmatized (Lefley H.P. 1987; Wahl O.F., Harman C.R. 1989). Their lives are disrupted by providing more care than would normally be appropriate for someone of the patient's age. In those cases where the reciprocity between family members is out of balance, normal care changes to care-giving. The addition of the care-giving role to already existing family roles becomes stressful; physically, psychologically and economically (Clark R.E. 1994).

Historically and in contrast to their western counterparts, Indian caregivers have never been systemically excluded from the treatment of people with mental illness. A large part of the mental health care has thus always taken place in the community with the family as the primary care provider. National health policies have also tried to ensure that the locus of care continues to be with the family. Western studies have shown that about one-third to two-thirds of persons with schizophrenia and related psychotic disorders live with or have regular contact with a family caregiver (Dyck DG et al 1999; Barrowclough C. 2005) whereas the proportion of patients staying with their families is much higher (over 90\%) in countries like India or China (Shankar R, Rao K 2005).

This is due to the social and cultural milieu as well as the inadequate existing mental health infrastructure (Thara R., Srinivasan T.N. 1997). Shankar and Kamath (1991) reported on the "cure versus care" dichotomy, wherein caregivers stressed that it was the duty of professionals to cure their patient, while providing care was the role they assigned to themselves. Families in India are involved in most aspects of care for persons with several mental illnesses. They are recognized as having a prominent role to play in decisions regarding engagement or disengagement from the treatment process, supervision of medication, providing day to day care and emotional support to the individual. (Nunley M. 1998; Shankar R. 2002) 
Coping has been broadly defined as, cognitive and behavioral efforts to manage specific external or internal demands (and conflicts between them) that are appraised as taxing or exceeding the resources of a person (Lazarus R. 1991). Mediators of these processes include variables such as the caregiver's personal attributes, attitude towards caregiving and the degree of social support available for the carer etc. Interaction between stressors, appraisals and coping produce the eventual outcomes in terms of distress or well being. The coping strategies utilized by the caregivers are thus of importance, as they determine the impact of the stressor on the caregiver's health and adjustment which, in turn, may affect the caregiver's relationship with the ill family member (Provencher H.L. et al 2000; Scazufca M., Kuiper E. 1999). Such strategies have been classified in several different ways.

One fundamental way is to classify the coping strategies as either problem focused or emotion focused. The former refers to strategies where the emphasis is on finding solutions to the problem, while the later refers to the ways in which an individual regulates the emotional response to the problem situation (Lazarus R.S. 1993). In situations of chronic stress, emotion focused coping strategies are more likely to be adopted (Lepore S.J., Evans G.W. 1996; Stanton A.L. et al 2001).

There is a definite paucity of Indian studies looking into the coping repertoire of schizophrenic patients as a whole and its relationship with the socio-demographic variables. So the current study aims to study the same.

\section{Methodology}

\section{Population:}

The study was conducted in the psychiatry department of Dr. S.N.Medical College, Jodhpur. 100 patients with a diagnosis of schizophrenia and their caregivers were randomly selected from the patients admitted in the male and female wards of psychiatric centre, Jodhpur after obtaining an informed consent from them.

\section{Sampling Design:}

Non probability purposive sampling

\section{Inclusion criteria:}

1) Diagnosed as a case of Schizophrenia as per ICD-10 criteria.

2) First degree relative (parents, siblings or offspring) and spouses of the index patient actively involved in the care of the patient and living with the patients for at least 6 months prior to the assessment.

\section{Exclusion criteria:}

1) Substance induced disorder in patient.

2) Any co-morbid psychiatric or medical illness if present, in patient.

\section{Tools for Study:}

\section{(A) Patient's Socio-demographic Performa}

A socio-demographic Performa is developed to record details about the patient such as age, gender, education, marital status and area of residence. Information regarding diagnosis and duration of illness will also be recorded.

\section{(B) Caregiver Socio-demographic Performa}

This is used to record information about the caregiver, such as relationship to the index patient, age, gender, education, duration of marriage (for spouse caregivers) and duration of care.

\section{(C) Coping checklist}

The coping checklist (CCL) has 70 items describing a broad range of behavioral, cognitive and emotional coping responses that an individual might use to handle stress. The responses are scored dichotomously in a yes/no format, indicating whether a particular coping behavior is present or not. The test retest reliability for a 1 month period is $0.74(\mathrm{p}<0.01)$ and alpha for the total scale is 0.86 (Rao K et al 1989). The total no. of items reported by an individual is indicative of the size of coping repertoire. Further refinement of the tool resulted in seven subscales, one of problems focused coping, five of emotion focused coping and one social support subscale, which is a combination of both problems focused and emotion focused coping. The CCL will be used for present study to assess and understand the type of coping strategies used by caregivers to deal with stress of caregiving. It is comprehensive easily administered and covers coping behaviors specific to the social and cultural context as it was developed in the Indian setting. 


\section{Statistical Methods:}

Descriptive statistical analysis has been carried out in the present study. Results on continuous measurements are presented on Mean \pm SD and results on categorical measurements are presented in Number (\%). Significance is assessed at $5 \%$ level of significance. The statistical tests employed to find the significance of study parameters include, unpaired t-test, Analysis of variance (ANOVA), while Pearson's correlation coefficient was computed to find correlations between different variables.

\section{Results And Discussion}

Table 1 shows the socio-demographic characteristics of the total patient sample. $46 \%$ of the patients were between 20-29 years of age and 34\% were between 30-39 years. The majority of patients were male (84\%) with only $16 \%$ of the patients being female. Majority of the patients were of low educational status with $24 \%$ of them being illiterate, $34 \%$ educated up to primary level, $20 \%$ up to middle level, $8 \%$ up to senior secondary level and $14 \%$ of the patients had completed graduation. $74 \%$ of the patients were from rural background, $26 \%$ were urban. $70 \%$ of the patients were unemployed, which points towards the occupational and functional impairment caused by a chronic illness like schizophrenia.

Table 2 shows the socio-demographic characteristics of the caregivers. More than one third of the caregivers $(36 \%)$ were 50 years or above in age while $22 \%$ were between 40 to 49 years. The majority of caregivers were male $(78 \%)$ with only $22 \%$ of the caregivers being female. $74 \%$ of the caregivers were employed while $26 \%$ were unemployed.

Table 3 describes the distribution of caregivers on the basis of their relationship with the patient. Majority of the caregivers include parents (42\%) and siblings (34\%), $20 \%$ were spouses of patients and only $4 \%$ were son or daughter.

Table 4 shows the duration of caregiving. About two-third of the entire population of patients had been taken care for, for less than 10 years with $58 \%$ of them having been cared for, for less than 5 years. The mean duration of care was $6.62 \pm 5.37$ years. The average duration coincided with the duration of illness in the patient, indicating that these caregivers have been the stable and long term providers of care.

Table 5 shows the correlation between caregivers socio-demographic variables and their coping repertoire. A negative correlation was found between the age of caregivers and coping scores $(r=-0.47)$ which was statistically significant. Therefore the younger caregivers have a larger coping repertoire. No statistically significant difference was found in the coping scores between male and female caregivers. Caregivers with higher educational status experience larger coping repertoire with mean Coping score for graduate and postgraduate caregivers being $21.57 \pm 4.28$ and the difference between the groups was statistically significant. No statistically significant difference was found in the mean coping scores between urban and rural caregivers.

Table 6 shows the coping repertoire on the basis of caregivers' relationship with the patient and mean duration of caregiving. Highest mean coping score was found in the siblings and others (son/daughter) while parents reported least mean coping score. Spouses as a caregiver reported slightly higher mean coping score compared to parents but lesser than siblings. A negative correlation was found between the duration of care and the mean coping scores $(r=-0.17)$ though it was statistically insignificant $(p$ value $=0.24)$.

A larger coping repertoire indicates a broader range and variety of coping behaviors at the individual's disposal (Pearlin and Schooler, 1978) and suggests that such a person may be more flexible in his use of coping responses (Wheaton, 1983). Moreover, a large repertoire may be useless if it cannot be mobilized when most needed. This dimension needs to be examined in greater detail.

\section{Conclusion}

In the present study, more than one third of the caregivers (36\%) were 50 years or above in age and majority of them were males and of low educational status. A larger coping repertoire was found in younger caregivers and those with higher educational status. Highest mean coping score was found in the siblings and others (son/daughter) while parents reported least mean coping score.

One limitation of the present study is that it was done in a tertiary hospital, in an urban setting, and hence the results cannot be generalized to the population at large. The size of the sample was small and a multicentered study with a larger sample size is desired.

The above findings show that the quality of care given to the schizophrenic individuals rests on their primary care giver. It thus becomes essential to plan interventions that would increase their coping repertoire and thus improve their psychological well being. 


\section{References}

[1]. Barrowclough C. (2005). Families of people with schizophrenia. In: Sartorius N, Leff J, Lopez Ibor JJ, Okasha A, editors. Families and mental disorders: from burden to empowerment. John Wiley \& Sons Ltd. P1-24.

[2]. Clark R.E. (1994). Family costs associated with severe mental illness and substance abuse. Hospital and Community Psychiatry, 45:808-813.

[3]. Dyck DG, Short R, Vitaliano PP (1999). Predictors of burden and infectious illness in schizophrenia caregivers. Psychosomatic Medicine; 61:411-419.

[4]. Lazarus R. (1991). Emotion and adaptation. London: Oxford university Press.

[5]. Lazarus R. (1993). From psychological stress to the emotions: A history of changing outlooks. Annual Review of Psychology,44: 121.

[6]. Lepore SJ and Evans GW (1996). Coping with multiple stressors in the environment. In M.Zeider and N.S.Endler (Eds), Handbook of Coping: Theory, Research and Applications. New York: Willey.

[7]. Lefley, H.P. (1987). Aging parents as caregivers of mentally ill adult children: An emerging social problem. Hospital and Community Psychiatry, 38:1063-1070.

[8]. Lefley, H.P. (1989). Family burden and family stigma in major mental illness. American Psychologist, 44:556-560

[9]. Nunley M. (1998). The involvement of family in Indian psychiatry. Culture, Medicine and Psychiatry, 22:317-353.

[10]. Pearlin LI \& Schooler C. (1978). The structure of coping. J. Health Soc. Behavior; 19:2-21

[11]. Provencher, H.L., Fournier JP et al (2000). The caregiver's perception of behavioral disturbance in relatives with schizophrenia: A stress coping approach. Community Mental Health Journal, 36:293-306.

[12]. Rao K, Subbakrishna D.K. \& Prabhu GG (1989). Development of a Coping Checklist: A preliminary report. Indian Journal of Psychiatry; 31:128-133.

[13]. Scazufka M. and Kuipers E. (1999). Coping strategies in relatives of people with schizophrenia before and after psychiatric admission. British Journal of Psychiatry,17(4):154-158.

[14]. Shankar R (2002). Family Professional collaboration in India. In H.P.Lefley D.L.Johnson (Eds), family intervention in mental illness: International perspectives. Connecticut: Praeger Publishers.

[15]. Shankar R, Kamath S (1991). Needs based interventions with families of the chronic mentally ill. Presented at the Congress of the World Association of Psychosocial rehabilitation, Montreal. Oct. 14-18.

[16]. Shankar R, Rao K (2005). From burden to empowerment: the journey of family caregivers in India. In: Sartorius N, Leff J, Lopez Ibor JJ, Okasha A, editors. Families and mental disorders: from burden to empowerment. John Wiley \& Sons Ltd. P 259-90

[17]. Stanton A.L. et al (2001). Emotionally expressive coping predicts psychological and physical adjustment to breast cancer. Journal of Consulting and Clinical Psychology, 68:875-882.

[18]. Thara R \& Shrinivasan T.N. (1997). Outcome of marriage in schizophrenia. Social Psychiatry and Psychiatric Epidemiology, 32:416-420

[19]. Van Wijingaarden et al (2002). Caregiving consequences in Netherland and other European countries: The development and use of the Involvement Questionnaire. In H.P.Lefley D.L.Johnson (Eds), Family interventions in mental illness: International perspectives. Connecticut: Praeger Publishers.

[20]. Wahl O.F. and Harman C.R. (1989). Family views of stigma. Schizophrenia Bulletin, 15:131-139.

[21]. Wheaton B. (1983). Stress personal coping resources and psychiatric symptoms: An investigation of interactive models. Journal of health and social behavior; 208-229.

Table 1: Socio-demographic data of total patient sample

\begin{tabular}{|c|c|c|c|}
\hline \multicolumn{2}{|c|}{ Variables } & No. of patients $(n=100)$ & Percentage (\%) \\
\hline \multirow[t]{4}{*}{ Age in years } & $20-29$ & 46 & $46 \%$ \\
\hline & $30-39$ & 34 & $34 \%$ \\
\hline & $40-49$ & 10 & $10 \%$ \\
\hline & 50 and above & 10 & $10 \%$ \\
\hline \multirow[t]{2}{*}{ Gender } & Male & 84 & $84 \%$ \\
\hline & Female & 16 & $16 \%$ \\
\hline \multirow[t]{5}{*}{ Education } & Illiterate & 24 & $24 \%$ \\
\hline & Primary & 34 & $34 \%$ \\
\hline & Middle (up to $8^{\text {th }}$ ) & 20 & $20 \%$ \\
\hline & Sr. Secondary & 8 & $8 \%$ \\
\hline & Graduate and above & 14 & $14 \%$ \\
\hline \multirow[t]{2}{*}{ Residence } & Rural & 74 & $74 \%$ \\
\hline & Urban & 26 & $26 \%$ \\
\hline \multirow[t]{2}{*}{ Occupation } & Employed & 30 & $30 \%$ \\
\hline & Unemployed & 70 & $70 \%$ \\
\hline
\end{tabular}


Table 2: Socio-demographic details of the care givers.

\begin{tabular}{|c|c|c|c|}
\hline \multicolumn{2}{|c|}{ Variables } & \multirow{2}{*}{$\begin{array}{c}\text { No. of caregivers } \\
(\mathrm{n}=100) \\
18\end{array}$} & \multirow{2}{*}{$\begin{array}{c}\text { Percentage (\%) } \\
18 \%\end{array}$} \\
\hline Age in years & $20-29$ & & \\
\hline & $30-39$ & 24 & $24 \%$ \\
\hline & $40-49$ & 22 & $22 \%$ \\
\hline & 50 and above & 36 & $36 \%$ \\
\hline \multirow[t]{2}{*}{ Gender } & Male & 78 & $78 \%$ \\
\hline & Female & 22 & $22 \%$ \\
\hline \multirow[t]{5}{*}{ Education } & Illiterate & 36 & $36 \%$ \\
\hline & Primary & 20 & $20 \%$ \\
\hline & Middle (up to $8^{\text {th }}$ ) & 20 & $20 \%$ \\
\hline & Sr. Secondary & 10 & $10 \%$ \\
\hline & Graduate and above & 14 & $14 \%$ \\
\hline \multirow[t]{2}{*}{ Residence } & Rural & 74 & $74 \%$ \\
\hline & Urban & 26 & $26 \%$ \\
\hline \multirow[t]{2}{*}{ Occupation } & Employed & 74 & $74 \%$ \\
\hline & Unemployed & 26 & $26 \%$ \\
\hline
\end{tabular}

Table 3: Relationship of care givers with the patient

\begin{tabular}{|c|c|c|}
\hline Relationship & No. of caregivers (n=100) & Percentage (\%) \\
\hline Parents & 42 & $42 \%$ \\
\hline Spouse & 20 & $20 \%$ \\
\hline Sibling & 34 & $34 \%$ \\
\hline Other(Son/Daughter) & 4 & $4 \%$ \\
\hline
\end{tabular}

Table 4: Duration of caregiving in number of years.

\begin{tabular}{|c|c|c|}
\hline Duration of caregiving in years & No. of caregivers $(\mathbf{n}=\mathbf{1 0 0})$ & Percentage (\%) \\
\hline 0-5 years & 58 & $58 \%$ \\
\hline 6-10 years & 16 & $16 \%$ \\
\hline$>10$ years & 26 & $26 \%$ \\
\hline
\end{tabular}

Table 5: Correlations between caregiver socio-demographic variables and coping:-

\begin{tabular}{|c|c|c|}
\hline Variables & Mean Coping score \pm SD & Statistical Significance \\
\hline \multicolumn{3}{|l|}{ Age in years } \\
\hline $20-29$ & $21.44 \pm 4.33$ & \multirow{4}{*}{$\begin{array}{c}r=-0.47 \\
\mathrm{p} \text { value }=0.0006(\mathrm{~S})\end{array}$} \\
\hline $30-39$ & $20.08 \pm 3.61$ & \\
\hline $40-49$ & $17.18 \pm 4.40$ & \\
\hline 50 and above & $15.89 \pm 3.82$ & \\
\hline \multicolumn{3}{|l|}{ Gender } \\
\hline Male & $18.15 \pm 4.26$ & \multirow{2}{*}{$\begin{array}{c}\mathrm{t} \text {-value }=0.077 \\
\mathrm{p} \text { value }=0.94(\mathrm{NS})\end{array}$} \\
\hline Female & $18.27 \pm 5.39$ & \\
\hline \multicolumn{3}{|l|}{ Education } \\
\hline Illiterate & $16.33 \pm 4.23$ & \multirow[t]{5}{*}{$\mathrm{p}$ value $=0.015(\mathrm{~S})$} \\
\hline Primary & $16.40 \pm 3.98$ & \\
\hline Middle (up to $8^{\text {th }}$ ) & $20.50 \pm 3.92$ & \\
\hline Sr. Secondary & $19.00 \pm 3.67$ & \\
\hline Graduate and above & $21.57 \pm 4.28$ & \\
\hline \multicolumn{3}{|l|}{ Residence } \\
\hline Rural & $17.68 \pm 4.29$ & \multirow{2}{*}{$\begin{array}{c}\mathrm{t} \text {-value }=1.357 \\
\mathrm{p} \text { value }=0.18(\mathrm{NS})\end{array}$} \\
\hline Urban & $19.61 \pm 4.82$ & \\
\hline
\end{tabular}

Table 6: Correlation of coping on basis of caregiver's relationship with the patient and duration of care:-

\begin{tabular}{|c|c|c|}
\hline Variables & Mean Coping score \pm SD & Statistical Significance \\
\hline Relationship & $16.29 \pm 3.96$ & \multirow{2}{*}{ P value $=0.002$ (S) } \\
\hline Parents & $16.60 \pm 4.55$ & \\
\hline Spouse & $21.06 \pm 3.46$ & \\
\hline Othling & $21.50 \pm 4.95$ & \\
\hline Mean duration of caregiving & $18.18 \pm 4.47$ & $\begin{array}{c}\mathrm{r}=-0.17 \\
\mathrm{p} \text { value }=0.24 \text { (NS) }\end{array}$ \\
\hline 6.62 \pm 5.37 & &
\end{tabular}

